\title{
Relationship between fear of falling and quality of life in older women fallers fear of falling and quality of life in older
}

\begin{abstract}
Fear of falling common in older people and can be associated with poor quality of life.

Objectives: To evaluate the relation between fear of falling and the quality of life and if there is difference in the quality of live according with the level of fear of elder women with a history of falls.

Methods: The quality of life (SF36) and fear of falling (FES-I) were assessed in 22 older women fallers. The correlation between fear of falling and quality of life was made using Pearson and Sperman coefficient and the comparison by t test and by the Mann-Whitney test, with $\mathrm{p} \leq 0.05$.
\end{abstract}

Results: The data showed that of 8 domains of SF36, there was a significant correlation in four with the fear of falling. Was possible observed too that fallers elder with low concern had better scores in the SF36 than elders with high concern.
Volume I Issue 5 - 2017

\author{
Melina Galetti Prata,' Marcos Eduardo \\ Scheicher ${ }^{2}$ \\ 'Department of Physical Therapist, São Paulo State University, \\ Brazil \\ ${ }^{2}$ Department of Physical Therapy and Occupational Therapy, São \\ Paulo State University, Brazil
}

\begin{abstract}
Correspondence: Marcos Eduardo Scheicher, Department of Physical Therapy and Occupational Therapy, São Paulo State University, Brazil, CEP: I7525-000,

Email mscheiche@marilia.unesp.br
\end{abstract}

Received: June 26, 2017| Published: July 19, 2017

Conclusion: fear of falling maintains a relationship with the quality of life and that the greater the fear, worse the quality of life at the women elderly fallers.

Keywords: aging, accidental falls, quality of life, fear of falling

\section{Introduction}

Falls are a major public health problem among older adults. In addition to being the second cause of death due to accidental injury in the world, ${ }^{1}$ falls are also responsible for fractures, hospitalization, functional dependency and fear of falling,,$^{2,3}$ as well as direct and indirect costs. The falls occurrence in turn initiates a downward cycle towards losing independence and entering long-term care.

Fear of falling (FOF) is common in older people Vellas et al. ${ }^{4}$ indicated that fear of falling may lead to a loss of confidence and reduced activity, resulting in a loss of independence. Furthermore, fear of falling may lead to a decreased mobility ${ }^{5,6}$ functional decline ${ }^{5-7}$ falls $^{8}$ and institutionalization ${ }^{6}$ and consequently to a decrease in quality of life. ${ }^{5,6}$ The prevalence of fear of falling in communityliving elderly ranges between $12 \%$ and $65 \%$, and is higher in women than men. ${ }^{9}$ Older adults with a history of falling are twice as likely to express fear of falling compared with those who have no history of falls. ${ }^{10,11}$ Similarly, those reporting multiple falls or injurious falls are more likely to report fear of falling. ${ }^{11}$ However, fear of falling is not simply a consequence of experiencing a fall, as around $20 \%$ of older adults with no history of previous falls still express some fear of falling ${ }^{6}$, possibly because of the presence of psychological factors or suffered experience through friends or relatives who have fallen. ${ }^{11}$ Initially FOF was considered as post-fall syndrome, ${ }^{12}$ named ptophobia ${ }^{13}$ however, subsequent studies found that FOF could also be identified in older adults who have not fallen. ${ }^{8,11,14-16}$

FOF is reported to be associated with several adverse consequences, including mobility or activity restriction and the development of deconditioning, ${ }^{17-21}$ reduced social interactions, ${ }^{11,16,22}$ subsequent falls ${ }^{6,8,23}$ and a poor quality of life which was found to be related to further physical, psychological and mental function declines. ${ }^{6,16}$
Quality of life (QOL) has been conceived to represent the physical, mental and social indicators of an individual health status or health-related quality of life. ${ }^{24}$ As described above, fear of falling can interfere in the quality of life. There are fewer studies in the literature that correlate this two conditions and that compare the quality of life between different levels of fear. Therefore, the aim of the present study was to evaluate the relation between fear of falling and the quality of life and if there is difference in the quality of live according with the level of fear of elder women with a history of falls.

\section{Methods}

\section{Sample}

The quality of life and fear of falling of a convenience sample of 22 community dwelling female volunteers were assessed in a nonrandomized cross-sectional study.The volunteers, aged 60 or older, were recruited at primary health units, health centers, community centers for the older and geriatric clinics from the city of Marília, São Paulo, Brazil. A "faller" was defined as a person who had at least 1 fall in the last 12 months. ${ }^{25-27}$ The design of the study is illustrated in Figure 1 .

The inclusion criteria were: not perform oriented exercises currently and be able to walk independently, not have neurological or musculoskeletal disorders or pain that interfered with their daily activities, not have lower extremity joint replacement or orthostatic hypotension, have normal scores on the Mini-Mental State Examination (MMSE) $)^{28}$ and, at the time of testing, not use of drugs that interfere in the postural balance.

The written informed consent was obtained from all the participants before enrollment. The study was approved by the Research Ethics Committee of the Faculty of Philosophy and Sciences (Process $n^{\circ}$ 
0386/2011), Universidade Estadual Paulista (UNESP), Marília, São Paulo, Brazil and it was conducted in accordance with Resolution No. 196/96 of the National Health Council.

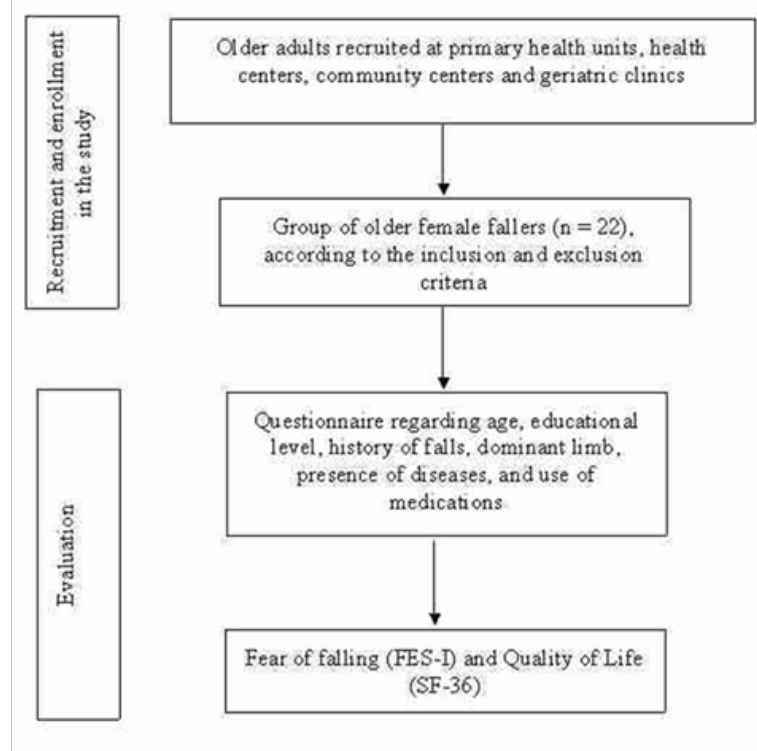

Figure I Data collection procedures.

\section{Data collection}

All evaluation occurred in the clinic of Physical Therapy at University between May and August of 2015. Initially, the participants answered a questionnaire regarding age, educational level, history of falls, dominant limb and presence of diseases and use of medications. All evaluations were made by the same trained Physical therapist.

Quality of life was assessed with the questionnaire Medical Outcomes Survey Short-form General Health Survey (SF-36), translated and validated for the Portuguese-Brazil by Ciconelli et al. ${ }^{29}$ The SF-36 is a multi-item scale questionnaire that evaluates points of several clinical components such as functional capacity, physical activities, bodily pain, general state of health, vitality, social and emotional problems and mental health, evaluated by transforming the responses scores from 0 to 100 , where zero corresponds to the "worst" and 100 to the "best" health.

The fear of falling was assessed using the Falls Efficacy ScaleInternational (FES-I) that evaluates the level of concern about the possibility of falling when performing 16 activities. The level of concern is measured on a scale from one to four. The total score ranges from 16 (no concern) to 64 (extreme concern). ${ }^{30}$

\section{Statistical analysis}

Statistical analysis was performed using the Graph Pad Instat ${ }^{\circledR} 3.1$ software. The Shapiro-Wilk test was used to evaluate the normality of the data. Correlations were made by the Pearson test for normally distributed data and by the Spearman test for not normally distributed data. The strength of the correlation coefficient was: 0.9 to 1.0 (-0.9 to-1.0): very high positive (negative) correlation; 0,7 to 0.9 (-0.7 to - 0.9): high positive (negative) correlation; 0.5 to 0.7 ( -0.5 to -0.7$)$ : moderate positive (negative) correlation; 0.3 to 0.5 ( -0.3 to -0.5$)$ : low positive (negative) correlation and 0.0 to 0.3 ( 0.0 to -0.3$)$ : negligible correlation. ${ }^{31}$ The cut-off of FES-I was 16-22 to low concern and 2364 to high concern. ${ }^{32} \mathrm{~A}$ level of significance of $\mathrm{p} \leq 0.05$ was adopted.

\section{Results}

Mean (SD) for age, MMSE, FES-I score and number of falls were 72.36(5.1), 27.2(2.3), 23.7(4.6) and 2.3(1.2) respectively. The Table 1 shows the coefficient correlation between the domains of SF-36 and the fear of falling. Its possible observes that of 8 domains, there was a significant correlation in four, indicating a strong relation between fear of falling and quality of life. The Table 2 shows the comparison of scores of quality of life between elders with low and high concern about fear of falling. The results show that the greater the fear, worse the quality of life.

Table I Correlations between FES-I and scores of SF-36

\begin{tabular}{lll}
\hline & FES-I & P \\
\hline Physical functioning & -0.69 & 0.01 \\
Role functioning & -0.23 & 0.47 \\
Bodily pain & $-0.5 \mathrm{I}$ & 0.1 \\
General health & -0.37 & 0.25 \\
Vitality & -0.06 & 0.83 \\
Social functioning & -0.72 & 0.01 \\
Role emotional & -0.75 & 0.007 \\
Mental health & -0.55 & 0.007 \\
\hline
\end{tabular}

FES-I, Falls efficacy scale international

Table 2 Comparison of scores of quality of life between low and high concern of fear of falling

\begin{tabular}{llll}
\hline & $\begin{array}{l}\text { Low concern } \\
\text { mean (SD) }\end{array}$ & $\begin{array}{l}\text { High concern } \\
\text { mean (SD) }\end{array}$ & P \\
\hline Physical functioning & $80.0(10.0)$ & $57.5(14.4)$ & 0.01 \\
Role functioning & $65.0(37.9)$ & $41.6(37.6)$ & 0.46 \\
Bodily pain & $69.2(20.1)$ & $49.8(17.2)$ & 0.12 \\
General health & $68.2(22.5)$ & $64.0(27.2)$ & 0.78 \\
Vitality & $51.0(13.8)$ & $52.5(15.1)$ & 0.86 \\
Social functioning & $85.0(10.4)$ & $50.0(17.6)$ & 0 \\
Role emotional & $76.6(22.3)$ & $33.3(36.5)$ & 0.05 \\
Mental health & $76.0(7.4)$ & $54.0(19.3)$ & 0.04 \\
\hline
\end{tabular}

\section{Discussion}

Falls may decrease the quality of life in older because who falls can develop fear of falling, social isolation, besides decrease functional independence. Fear of falling (FOF) is reported to be associated with several adverse consequences, including mobility or activity restriction and the development of deconditioning, ${ }^{17-21}$ reduced social interactions, ${ }^{11,16,22}$ subsequent falls ${ }^{6,8,22,23}$ and a poor quality of life which was found to be related to further physical, psychological and mental function declines. ${ }^{6,16}$

The results obtained in this study confirm a close relationship between FOF and quality of life in the elder population with falls history. Was observed correlation between FOF and physical functioning (PF), social functioning (SF), role emotional (RE) and 
mental health (MH). Physical functioning is associated with in performing all physical activities, including bathing or dressing. Our results showed a moderate relationship between FOF and physical functioning, suggesting that a person with FOF can decrease your activities of daily life such as those described above. Social functioning is associated with social activities and defines an individual's interactions with their environment and the ability to fulfill their role within such environments as work, social activities, and relationships with partners and family. ${ }^{33}$ Howland et al. ${ }^{22}$ found that fear of falling was a stronger predictor of non-participation in social activities than a history of falls. Our data showed a strong correlation between FOF and social functioning.

The role emotional (RE) domain evaluates problems with work or other activities as a result of emotional problems, while the mental health $(\mathrm{MH})$ expresses how much feelings of nervousness and depression are present because the situation. As our results showed a strong correlation between FOF and role emotional and a moderate correlation between FOF and mental health, it is clear the interference of fear in the psychological area.

Fear of falling in elderly people has been recognized as an important psychological factor. The psychological consequences related to falling, or the prospect of sustaining a fall, may be as disabling as, and sometimes more disabling than the fall itself. . $^{6,34}$ Older people who express fear of falling often express lower confidence in their ability to perform activities without falling than those who are not afraid ${ }^{10}$ and they habitually restrict the amount or type of physical activity they undertake, ${ }^{35,36}$ possibly leading to further falls. ${ }^{37}$

Our data showed that the level of concern implies in better or worse quality of life. We showed that fallers elder with low concern had better scores in the SF-36 scores than elders with high concern (Table 2). It could be seen in seven of eight domains of questionnaire and in 4 domains with statistical significance. This indicate that the greater the concern about falling, worse the quality of life. Chang et al. ${ }^{38}$ Comparing elder with and without FOF concluded that subjects with FOF had lower scores for SF-36 in 8 concepts than non-FOF subjects, both for male and female subjects. Our data are in agreement with other studies, that suggest that individuals with high levels of fear of falling are most likely to experience poor quality of life. ${ }^{39,40}$ FOF has been recognised as an importante psychological and physical factor that interfere in the quality of life.

Both falls and fear of falls can substantially reduce quality of life and independence and so contribute to the placement of an elderly person into nursing home. The FOF may reflect a rational appraisal of reduced functional abilities of older or, alternatively, may be irrational, excessive, or phobic. Excessive fear of falling can lead to needless restriction in participation in physical and social activities ${ }^{41}$ resulting in physical deconditioning ${ }^{6,42}$ poor quality of life ${ }^{5,6,41,42}$ social isolation, depression, and psychological distress.

\section{Conclusion}

We can conclude that the fear of falling maintains a relationship with the quality of life and that the greater the fear, worse the quality of life at the women elderly fallers.

\section{Acknowledgements}

None

\section{Conflict of interest}

The authors declared that there is no conflict of interest in publishing their manuscript.

\section{References}

1. WHO. Falls. World Health Organization, Switzerland; 2017.

2. Masud T, Morris R. Epidemiology of falls. Age Ageing. 2001;30(4):3-7.

3. Perracini M, Ramos L. Fatores associados a quedas em uma coorte de idosos residentes na comunidade. Revista de Saúde Pública. 2002;36(6):709-716

4. Vellas B, Cayla F, Bocquet H, et al. Prospective study of restriction of acitivty in old people after falls. Age Ageing 1997;16(3):189-193.

5. Arfken C, Lach H, Birge S, et al. The prevalence and correlates of fear of falling in elderly persons living in the community. Am J Public Health. 1994;84(4):565-570.

6. Cumming R, Salkeld G, Thomas M, et al. Prospective Study of the Impact of Fear of Falling on Activities of Daily Living, SF-36 Scores and Nursing Home Admission. J Gerontol A Biol Sci Med Sci. 2000;55(5):299-305.

7. Carlos FM, Seeman T, Baker D, et al. Self-efficacy, Physical Decline, and Change in Functioning in Community-Living Elders: A Prospective Study. J Gerontol B Psychol Sci Soc Sci. 1996;51(4):183-190.

8. Friedman S, Munoz B, West S, et al. Falls and Fear of Falling: Which Comes First? A Longitudinal Prediction Model Suggests Strategies for Primary and Secondary Prevention. J Am Geriatr Soc. 2002;50(8):1329-1335.

9. Legters K. Fear of Falling. Phys Ther. 2002;82(3):264-272.

10. Lachman M, Howland J, Tennstedt S, et al. Fear of Falling and Activity Restriction: The Survey of Activities and Fear of Falling in the Elderly (SAFE). J Gerontol B Psychol Sci Soc Sci. 1998;53(1):43-50.

11. Howland J, Lachman M, Peterson E, et al. Covariates of Fear of Falling and Associated Activity Curtailment. Gerontologist. 1998;38(5):549-555.

12. Murphy J, Isaacs B. $\quad$ The Post-Fall Syndrome. Gerontology. 1982;28(4):265-270.

13. Bhala R, Donnell OJ, Thoppil E. Ptophobia. Phobic fear of falling and its clinical management. Phys Ther. 1982;62(2):187-190.

14. Tinetti M, Speechley M, Ginter S. Risk Factors for Falls among Elderly Persons Living in the Community. $N$ England $J$ Med. 1988;319(26):1701-1707.

15. Lawrence R, Tennstedt S, Kasten L, et al. Intensity and Correlates of Fear of Falling and Hurting Oneself in the Next Year: Baseline Findings from a Roybal Center Fear of Falling Intervention. J Aging Health. 1998;10(3):267-286.

16. Scheffer A, Schuurmans M, Dijk VN, et al. Fear of falling: measurement strategy, prevalence, risk factors and consequences among older persons. Age Ageing. 2007;37(1):19-24.

17. Zijlstra G, Haastregt J, Eijk J, et al. Prevalence and correlates of fear of falling, and associated avoidance of activity in the general population of community-living older people. Age Ageing. 2007;36(3):304-309.

18. Costa ME, Pepersack T, Godin I, et al. Fear of falling and associated activity restriction in older people. results of a cross-sectional study conducted in a Belgian town. Arch Public Health. 2012;70(1):1.

19. Vellas B, Wayne S, Romero L, et al. Fear of falling and restriction of mobility in elderly fallers. Age Ageing. 1997;26(3):189-193. 
20. Martin F. Fear of falling limiting activity in young-old women is associated with reduced functional mobility rather than psychologica factors. Age Ageing. 2005;34(3):281-287.

21. Curcio C, Gomez F, Reyes OC. Activity Restriction Related to Fear of Falling Among Older People in the Colombian Andes Mountains Are Functional or Psychosocial Risk Factors More Important? J Aging Health. 2009;21(3):460-479.

22. Howland J, Peterson E, Levin W, et al. Fear of Falling among the Community-Dwelling Elderly. J Aging Health. 1993;5(2):229-243.

23. Park MO, Xue X, Holtzer R, et al. Transient Versus Persistent Fear of Falling in Community-Dwelling Older Adults: Incidence and Risk Factors. J Am Geriatr Soc. 2011;59(7):1225-1231.

24. White S, Wójcicki T, Auley ME. Physical activity and quality of life in community dwelling older adults. Health Qual Life Outcomes. 2009;7(1):10.

25. Gonçalves D, Ricci N, Coimbra A. Equilíbrio funcional de idosos da comunidade: comparação em relação ao histórico de quedas. Brazilian Journal of Phys Ther. 2009;13(4):316-323.

26. Bekibele C, Gureje O. Fall Incidence in a Population of Elderly Persons in Nigeria. Gerontology. 2010;56(3):278-283.

27. Sai A, Gallagher J, Smith L, et al. Fall predictors in the community dwelling elderly: a cross-sectional and prospective cohort study. $J$ Musculoskelet Neuronal Interact. 2010;10(2):142-150.

28. Brucki S, Nitrini R, Caramelli $\mathrm{P}$, et al. Sugestões para o uso do mini-exame do estado mental no Brasil. Arq Neuro Psiquiatr. 2003;61(3):777-781.

29. Ciconelli R, Ferraz M, Santos W, et al. Tradução para a língua portuguesa e validação do questionário genérico de avaliação de qualidade de vida SF-36 (Brasil SF-36). Rev Bras Reumatol. 1999;39(3):143-150.

30. Camargos F, Dias R, Dias J, et al. Adaptação transcultural e avaliação das propriedades psicométricas da Falls Efficacy Scale - International em idosos Brasileiros (FES-I-BRASIL). Rev Bras Fisioter. 2010;14(3):237-243

31. Mukaka M. A guide to appropriate use of Correlation coefficient in medical research. Malawi Med J. 2012;24(3):69-71.
32. Delbaere K, Close J, Mikolaizak A, et al. The Falls Efficacy Scale International (FES-I). A comprehensive longitudinal validation study. Age Ageing. 2010;39(2):210-216.

33. Bosc M. Assessment of social functioning in depression. Compr Psychiatry. 2000;41(1):63-69.

34. Salkeld G, Cameron D, Cumming RG, et al. Quality of life related to fear of falling and hip fracture in older women: a time trade off study Commentary: Older people's perspectives on life after hip fractures. $B M J$. 2000;320(7231):341-346.

35. Tinetti M, Leon DC, Doucette J, et al. Fear of Falling and Fall-Related Efficacy in Relationship to Functioning Among Community-Living Elders. J Gerontol. 1994;49(3):140-147.

36. Tinetti M, Richman D, Powell L. Falls Efficacy as a Measure of Fear of Falling. J Gerontol. 1990;45(6):239-243.

37. Spanó A, Förstl H. Falling and the fear of it. Int $J$ Geriat Psychiatry. 1992;7(3):149-151.

38. Chang H, Chen H, Chou P. Factors Associated with Fear of Falling among Community-Dwelling Older Adults in the Shih-Pai Study in Taiwan. Plos One. 1992;11(3):e0150612.

39. Kempen G, Haastregt J, McKee K, et al. Socio-demographic, healthrelated and psychosocial correlates of fear of falling and avoidance of activity in community-living older persons who avoid activity due to fear of falling. BMC Public Health. 2009;9:170

40. Bagnoud LS, Eggimann BS, Rochat S, et al. Vulnerability in highfunctioning persons aged 65 to 70 years: the importance of the fear factor. Aging Clin Exp Res. 2010;22(3):212-218.

41. Yardley L, Smith H. A Prospective Study of the Relationship Between Feared Consequences of Falling and Avoidance of Activity in Community-Living Older People. Gerontologist. 2002;42(1):17-23.

42. Li F, Fisher K, Harmer P, et al. Fear of Falling in Elderly Persons: Association With Falls, Functional Ability, and Quality of Life. $J$ Gerontol B Psychol Sci Soc Sci. 2003;58(5):283-290. 